\title{
Microseismic Signal Characterization and Numerical Simulation of Concrete Beam Subjected to Three-Point Bending Fracture
}

\author{
Nuwen Xu, ${ }^{1,2}$ Feng Dai, ${ }^{1}$ Chun Sha, ${ }^{3}$ Yingcheng Lei, ${ }^{3}$ and Biao Li ${ }^{1}$ \\ ${ }^{1}$ State Key Laboratory of Hydraulics and Mountain River Engineering, College of Water Resource and Hydropower, \\ Sichuan University, Chengdu, Sichuan 610065, China \\ ${ }^{2}$ College of Civil Engineering, Shandong University, Jinan, Shandong 250016, China \\ ${ }^{3}$ Power China Chengdu Engineering Corporation Limited, Chengdu, Sichuan 610072, China
}

Correspondence should be addressed to Feng Dai; fengdai@scu.edu.cn

Received 11 September 2014; Accepted 22 November 2014

Academic Editor: Fei Dai

Copyright (C) 2015 Nuwen Xu et al. This is an open access article distributed under the Creative Commons Attribution License, which permits unrestricted use, distribution, and reproduction in any medium, provided the original work is properly cited.

\begin{abstract}
To study the generation mechanism and failure mode of cracks in mass concrete, microseismic monitoring is conducted on the fracture processes of the three-point bending roller compacted concrete (RCC) beam of Guanyinyan hydropower station. The spectrum characteristics of microseismic signals in different deformation and failure stages of the concrete beam are analyzed, and the identification method of the fracture stages and crack propagation precursors of concrete beam is established. Meanwhile, the Realistic Failure Process Analysis code (RFPA) is adopted to simulate and analyze the entire failure processes of concrete beam from its cracks initiation, development, propagation, and coalescence, until macroscopic fractures formation subjected to three-point bending test. The relation curve of the load, loaded displacement, and acoustic emission (AE) of concrete beam in the three-point bending test is also obtained. It is found that the failure characteristics of concrete beam obtained from numerical experiments agree well with the field physical test results. The heterogeneity of concrete is the major cause of zigzag propagation paths of beam cracks subjected to three-point bending tests. The results lay foundation for further exploring the formation mechanism of dam concrete cracks of Guanyinyan hydropower station.
\end{abstract}

\section{Introduction}

In recent years, hosts of ultra-large hydropower projects are being constructed or to be completed and put into operation in the southwest of China. Therefore, the engineering sector has always attached great importance to and been committed to resolving the dam body security and stability problems $[1,2]$. Most of these dams are located in western alpine valleys. The dam body is usually designed to be the concrete gravity dam or arch dam, which may lead to dam concrete cracking during construction of the concrete dam due to some factors including temperature control, grouting uplift, and structural distortion. The existence of cracks in the dam body not only worsens the appearance and damages the overall continuity of the dam but also weakens the stability and impermeability of the dam. The hydrostatic pressure in the crack (i.e., the horizontal crack) increases the displacement of the dam crest towards downstream, thus reducing the role of beams in the dam. Crack leakage makes calcium ion in concrete separate out and run away, may cause dam leakage and shorten the dam service life, and may even affect the dam security and restrict the later safe operation of the hydropower station [3]. Taking Xiaowan hydropower station arch dam for example, there are many arch cracks with about $1 \mathrm{~mm}$ average width in the middle of the dam body below an elevation of $1095.0 \mathrm{~m}$, causing the failure to full reservoir and normal operation to the dam and serious economic loss [4]. Some arch dams also generate cracks after long-time running, such as Side arch dam and Shangbiao arch dam [5, 6]. Currently, extensive use of conventional measurement technology, such as multiple position extensometers, convergence meter, and surface subsidence monitoring, is found to be very useful in the surface deformation monitoring of concrete dam. However, it is unrealistic for them to monitor the occurrence of microfractures effectively in deep concrete of dam prior to the formation of a macroscopic fracture outside 
the dam surface. With regard to concrete dams, these internal microfractures may often lead to macroscopic instability of dam. Consequently, there must be an intrinsic correlation between dam surface deformation and its internal microfractures (microseismicity). It is well known that brittle materials (i.e., rock or concrete) loaded in a testing machine and brittle structures that are stressed emit detectable acoustic or seismic signals. If these signals can be recorded sufficiently clearly as seismograms by a number of sensors, the original time of seismic event, and its location, source parameters such as source radius and dynamic stress drop can be estimated $[7,8]$. Thus, microseismic monitoring technique has been attempted to locate such fractures in concrete engineering practices.

During the past two decades, microseismic monitoring technique emerged from a pure research means to a mainstream industrial tool for daily safety monitoring for various geotechnical engineering. It has wide engineering applications in South Africa, Canada, Japan, Australia, and America. Some achievements have been obtained in rock slopes [9-11], underground mining $[8,12-14]$, tunnels [15, 16], oil and gas exploration and development [17], and electricity generation by hot dry rock [18], and so forth. Dam concrete is brittle and the apparent displacement is usually small when a microfracture occurs internally. As the concrete microfracture constantly propagates, a large number of microfractures are usually formed around the fracture before a macroscopic crack zone is formed. Microseismic monitoring can capture signals during the process from initiation, development, propagation, and coalescence of these concrete microfractures in real time. Then, the occurrence time, position, and properties of the concrete microfractures can be obtained through back calculation. However, there is no precedent for monitoring cracks in the mass concrete dam by using the microseismic monitoring technology.

There are two kinds of methods to identify the concrete crack sign. One is to analyze hypocenter parameters of the microfracture, including the size, intensity, energy, magnitude, apparent stress, and stress drop, qualitatively deducing the development trend of the crack and macroscopic fracture, and then forecast the evolution rules of dam body concrete local failure or cracks. This kind of method has been successfully applied to engineering fields including the mine and hydropower projects $[10,19,20]$. The other is to reveal the microseismic signal characteristics in each stage of the concrete failure by using the modern digital signal processing and analyzing technologies such as timefrequency analysis, random signal analysis, Higher-Order Statistics (HOS) analysis, and fractal analysis. The concrete microseismic signal is nonstationary and random, which contains much information about the concrete fractures. Therefore, the conventional time-domain statistical parameters have some uncertainty. Many scholars [21-23] adopted the frequency spectrum analysis technology (Fourier transform) to analyze microseismic signals generated during rock fractures or frequency spectrum characteristics of AE signals and achieved some understandings. For instances, when the studied rock from small scale to a larger scale, $\mathrm{AE}$ signals shift from high frequency to low frequency. The time-frequency characteristics of microseismic signals during concrete failure are different from those during rock failure, which is mainly determined by the composition characteristics of concrete materials. Concrete is a brittle composite material formed by hardening a compound mixed with cementing materials, aggregate, water, required chemical admixture, and mineral admixture in a proper proportion. Studies show that the concrete failure process is composed of two processes: cement and cement or cement and aggregate falling off. The microseismic signals sent from these two processes can be effectively distinguished on the spectrogram.

This study attempts to analyze the spectrum characteristics of microseismic signals during the fracture processes of the concrete beam subjected to three-point bending test. The mechanical behavior of concrete beam fracture from microfracture initiation, development, and propagation until coalescence to form macroscopic cracks is revealed. Moreover, the entire fracture processes of concrete beam subjected to three-point bending tests using 3D numerical simulation are also reproduced, which lays foundation for studying the formation mechanism and evolution rules of cracks in mass concrete.

\section{The Time-Frequency Analysis Principle of $S$ Transform}

$S$ Transform is an overtime window Fourier transform method [24], proposed by Stockwell et al. in 1996. This method is the extension of continuous wavelet transform with Morlet wavelet as its basic wavelet. $S$ Transform integrates the advantages of the short-time Fourier transform (STFT) and wavelet transform. It is mainly manifested as follows: its wavelet basis function adaptively reduces the analysis time width as the frequency increases and the timefrequency window is adaptive and does not need to meet wavelet admissible conditions.

In the geophysical prospecting field, $S$ Transform has had many successful applications. For instances, Tan et al. [25, 26] applied $S$ Transform to seismic data denoising and achieved better effect. Castagna et al. $[27,28]$ summarized the low frequency shadow rule on the oil-gas layer with $S$ Transform and successfully guided petroleum exploration and production practices. Pinnegar and Mansinha [29] detected the arrival time of the longitudinal wave in the natural earthquake. Andria et al. [30] determined the thickness of the thin layer with $S$ Transform in reservoir prediction, as well as detecting and identifying various transient signals.

$S$ Transform can be expressed as phase correction of continuous wavelet transform. $S$ Transform of function $h(t)$ is expressed as

$$
S(t, f)=\int_{-\infty}^{\infty} h(\tau) w(\tau-t) \exp (-i 2 \pi f \tau) d \tau
$$


where

$$
\begin{gathered}
w(\tau)=\frac{1}{\sigma \sqrt{2 \pi}} \exp \left(-\frac{t^{2}}{2 \sigma^{2}}\right), \\
\sigma(f)=\frac{1}{|f|} .
\end{gathered}
$$

The following equation can be obtained after substituting (2) into (1):

$$
\begin{aligned}
S(t, f)= & \int_{-\infty}^{\infty} h(\tau) \frac{|f|}{\sqrt{2 \pi}} \exp \left(-\frac{(\tau-t)^{2} f^{2}}{2}\right) \\
& \times \exp (-i 2 \pi f \tau) d \tau .
\end{aligned}
$$

Set $W(v)$ to Fourier transform of $w(t)$; that is,

$$
W(v)=\exp \left(-\frac{2 \pi^{2}}{f^{2}} v^{2}\right) .
$$

In the preceding equation, $v$ and $f$ have the same unit.

The window function of $S$ Transform must meet the following conditions:

$$
\int_{-\infty}^{\infty} w(\tau-t, f) d \tau=1
$$

Therefore, $S$ Transform can be written as

$$
\begin{aligned}
\int_{-\infty}^{\infty} S(t, f) d t= & \int_{-\infty}^{\infty} h(\tau) \exp (-i 2 \pi f \tau) \\
& \times \int_{-\infty}^{\infty} w(\tau-t, f) d \tau d t \\
& =\int_{-\infty}^{\infty} h(\tau) \exp (-i 2 \pi f \tau) d t=H(f) .
\end{aligned}
$$

Equation (6) actually provides the transformational relation between $S$ Transform and Fourier transform. In addition, (6) can ensure the reversibility of $S$ Transform.

Based on the mutual transformation process of STFT in the time domain and frequency domain, the following expression of $S$ Transform in the frequency domain can be obtained:

$$
\begin{aligned}
S(t, f) & =\int_{-\infty}^{\infty} H(v+f) W(v) \exp (i 2 \pi v t) d v \\
& =F^{-1}[H(v+f) W(v)] .
\end{aligned}
$$

In the preceding equation, $F^{-1}$ refers to Fourier inversion, $h(t)$ refers to the concrete microseismic signal to be analyzed, $\tau$ and $f$ refer to time and frequency, respectively, and $S(t, f)$ is $S$ matrix of one-dimensional concrete microseismic signals after $S$ Transform. $S$ matrix is obtained from concrete microseismic signals after $S$ Transform. $S$ modular matrix indicating the amplitude varying with time and frequency is obtained after a modulo operation on each element in $S$ matrix. $S$ modular matrix can be used to determine the
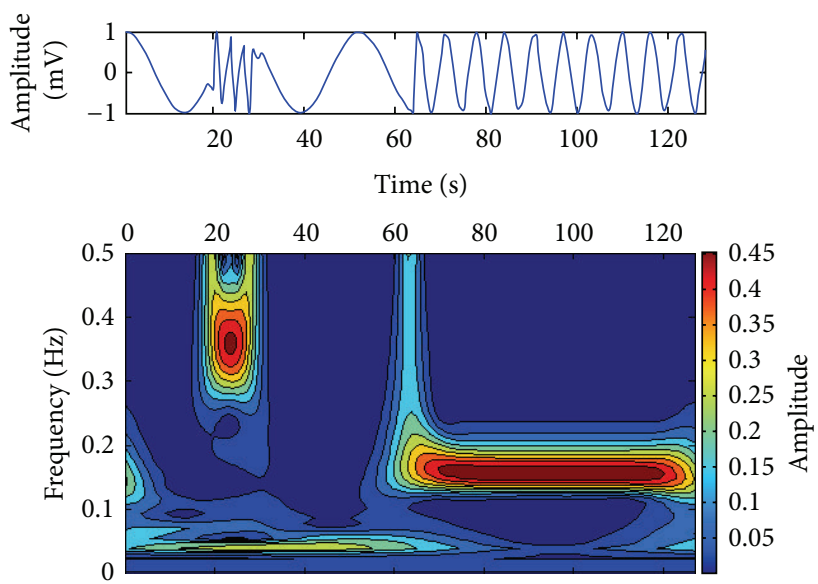

FIGURE 1: Spectrum characteristics of composite signal after $S$ Transform.
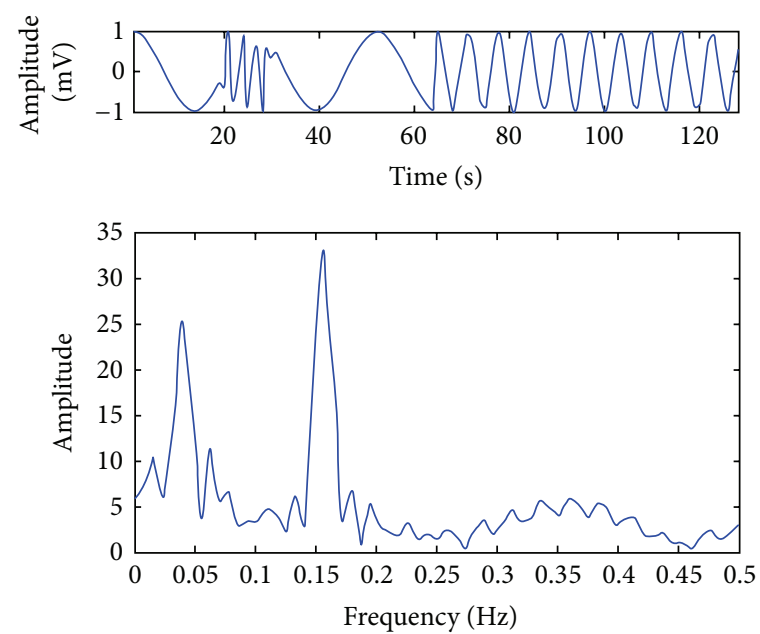

FIGURE 2: Spectrum characteristics of composite signal after Fourier transform.

distribution characteristics of concrete microseismic signals on the time-frequency plane.

Figure 1 shows one-dimensional composite signal $h(t)$ and its spectrum characteristics after $S$ Transform. Figure 2 shows the spectrum characteristics of this signal after Fourier transform. A one-dimensional signal $h(t)$ contains three frequency components: the dominant frequency of $0 \sim 20 \mathrm{~s}$ and $32 \sim 64 \mathrm{~s}$ signal is $0.045 \mathrm{~Hz}$; that of $20 \sim 30 \mathrm{~s}$ signal is $0.36 \mathrm{~Hz}$; and that of $64 \sim 128 \mathrm{~s}$ signal is $0.16 \mathrm{~Hz}$. According to Figures 1 and 2, S Transform spectrogram can effectively separate three dominant frequencies $(0.045 \mathrm{~Hz}, 0.16 \mathrm{~Hz}$, and $0.36 \mathrm{~Hz}$ ) from each other with consistent time. Three dominant frequencies (obvious $0.045 \mathrm{~Hz}$ and $0.16 \mathrm{~Hz}$ and inconspicuous $0.36 \mathrm{~Hz}$ ) rather than the occurrence time of each dominant frequency can be identified from Fourier transform spectrogram. Therefore, adopting $S$ Transform can effectively analyze microseismic signals and obtain their dominant frequencies and occurrence times accurately. 

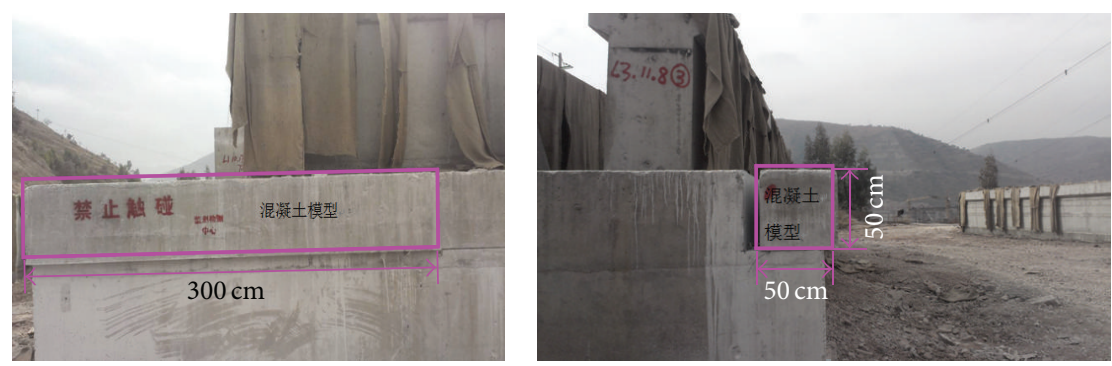

FIGURE 3: Preparation of the concrete beam specimen.

\section{Microseismic Signal Characteristics of Concrete Beam Subjected to Three-Point Bending Fracture}

3.1. Concrete Beam Preparation. The concrete beam is cut and extracted from the RCC of the cast-in-place dam in Guanyinyan hydropower station. The dimensions of the beam model are $300 \mathrm{~cm} \times 50 \mathrm{~cm} \times 50 \mathrm{~cm}$ (length $\times$ width $\times$ height) The strength grade is designed to be C25 (90 days). The age of the model already exceeds 400 days when the three-point bending fracture test is conducted on the concrete beam, as shown in Figure 3.

The three-point bending failure test adopts the hierarchical load-keeping method. Hierarchical load complies with the following principles: (1) $20 \mathrm{kN}$ is loaded each time on the $0 \sim 60 \mathrm{kN}$ stage, stopped 5 minutes halfway. (2) $10 \mathrm{kN}$ is loaded each time on the $60 \sim 140 \mathrm{kN}$ stage, stopped 5 minutes halfway. (3) $5 \mathrm{kN}$ is loaded each time on the $140 \sim 155 \mathrm{kN}$ stage, stopped 10 minutes halfway. (4) The load is adjusted in real time according to microseismic monitoring data, and the next loading is performed until the changes of strain data and microseismic data keep stable.

3.2. Microseismic Monitoring System. The IHMS microseismic monitoring system produced by YueYang Aocheng Technology Co., Ltd. is used to monitor and analyze microseismic signals during the three-point bending fracture processes of the concrete beam in real time. This system is mainly composed of the data acquisition system, data remote transmission system, and data processing and analysis system. Figure 4 shows the layout of the microseismic monitoring system. The main parameters of the microseismic system include the sampling frequency $(40 \mathrm{kHz})$, transducer sensitivity $(30 \mathrm{~V} / \mathrm{g})$, and transducer threshold $(20 \mathrm{mv})$. The P-wave velocity is $4800 \mathrm{~m} / \mathrm{s}$ that is determined by acoustic wave tests. For details about the microseismic monitoring principles and parameters, refer to $[10,11]$ in References.

The microseismic monitoring transducers are installed on both ends of the concrete beam. The installation positions are ground flush with a polisher, and gypsum is used to fix the transducers. Figure 5 shows the installation positions of the transducers. A rectangular coordinate system as shown in Figure 5 is set up with the lower left corner as the origin of coordinates $(0,0,0)$ to conduct positioning analysis on microseismic signals during the fracture processes of the concrete beam.

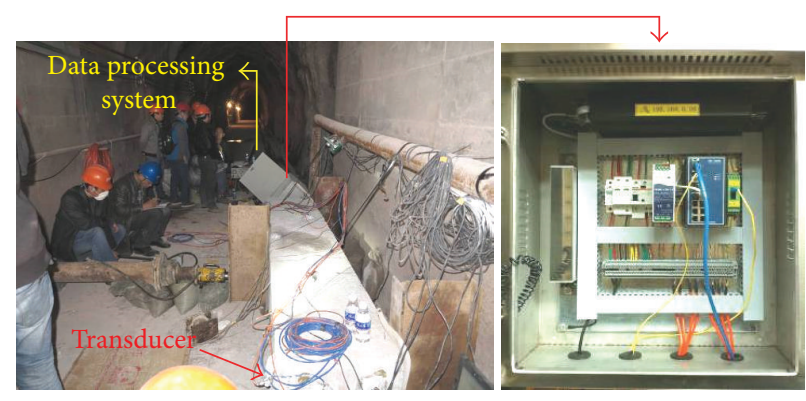

FIGURE 4: Microseismic monitoring system network.

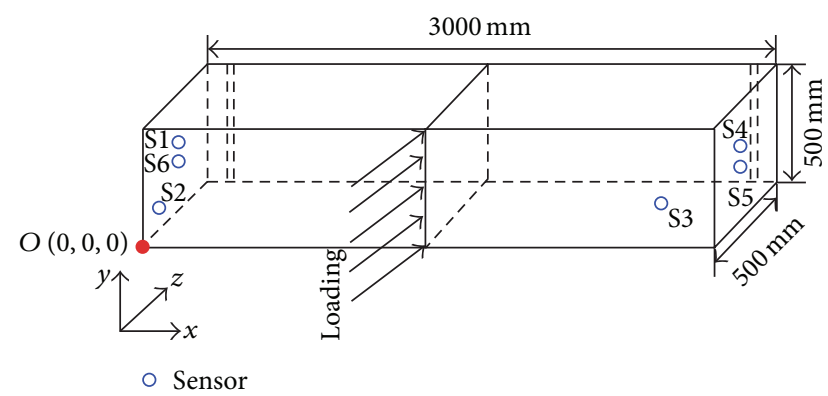

FIGURE 5: Layout of the microseismic monitoring transducers installed at the concrete beam.

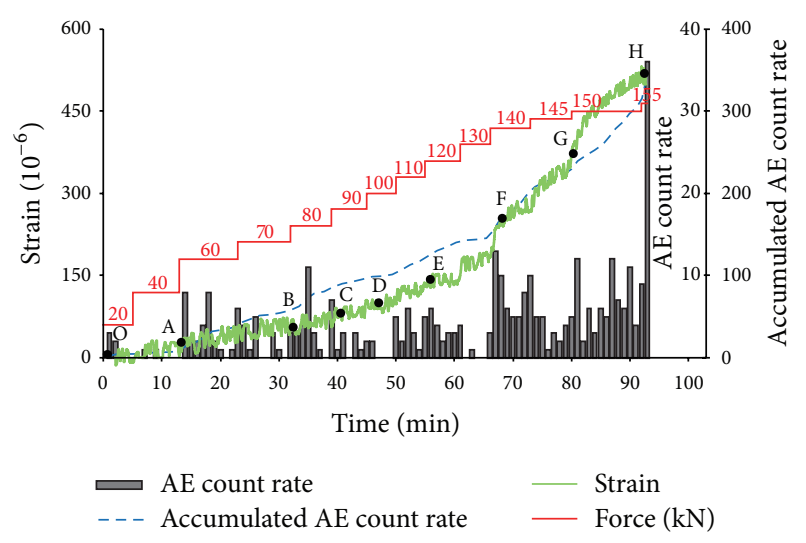

FIGURE 6: Characteristics of microseismic events during the failure processes of the concrete beam. 


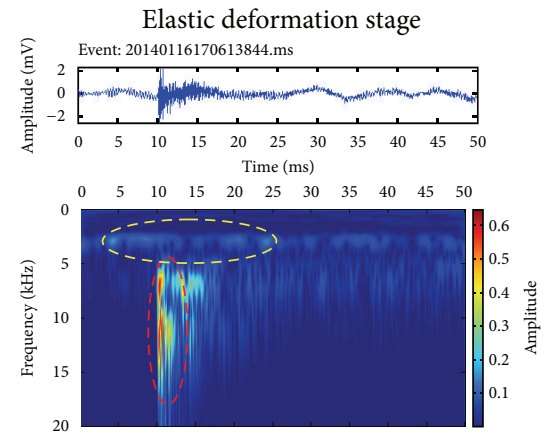

(a) $F=60 \mathrm{kN}, \sigma=0.39 \sigma_{c}$
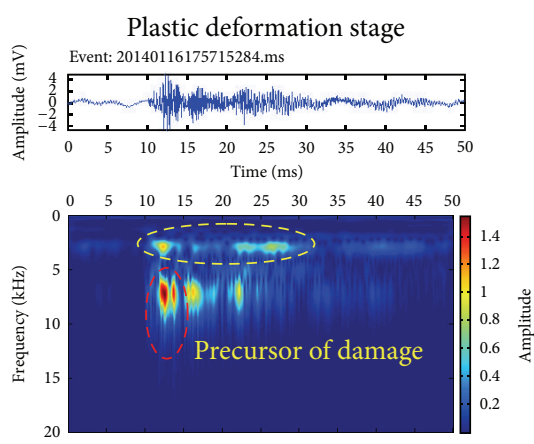

(d) $F=100 \mathrm{kN}, \sigma=0.65 \sigma_{c}$
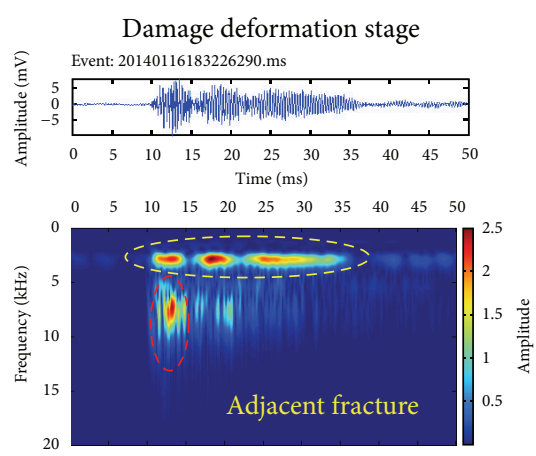

(g) $F=145 \mathrm{kN}, \sigma=0.94 \sigma_{c}$

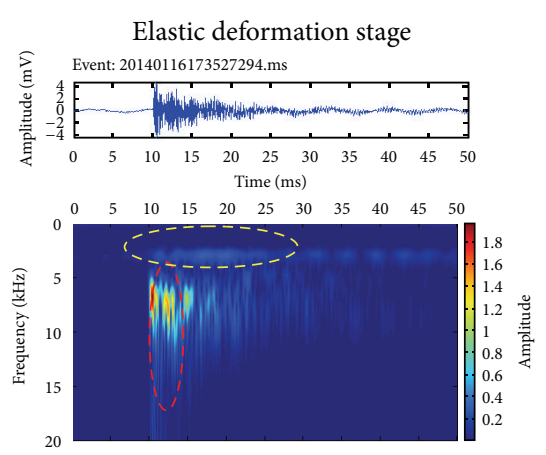

(b) $F=80 \mathrm{kN}, \sigma=0.52 \sigma_{c}$
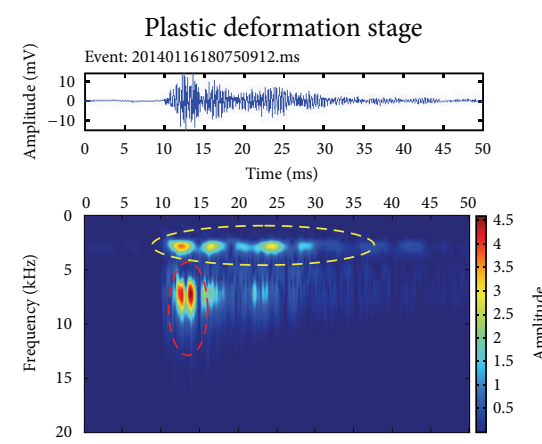

(e) $F=120 \mathrm{kN}, \sigma=0.77 \sigma_{c}$
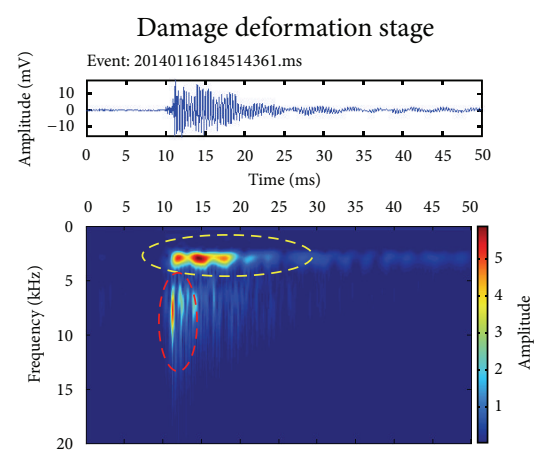

(h) $F=155 \mathrm{kN}, \sigma=\sigma_{c}$
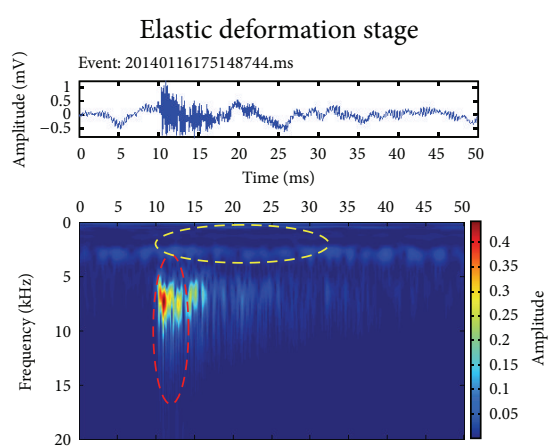

(c) $F=90 \mathrm{kN}, \sigma=0.58 \sigma_{c}$
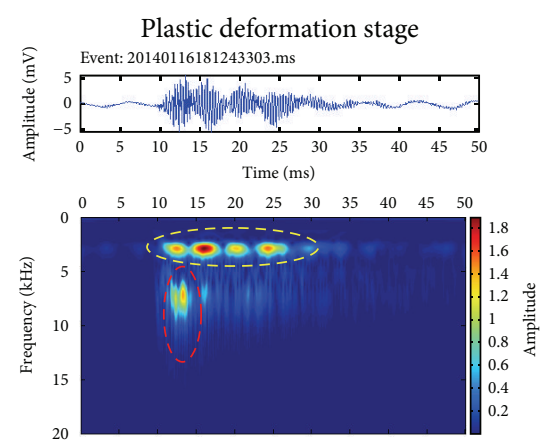

(f) $F=140 \mathrm{kN}, \sigma=0.90 \sigma_{c}$
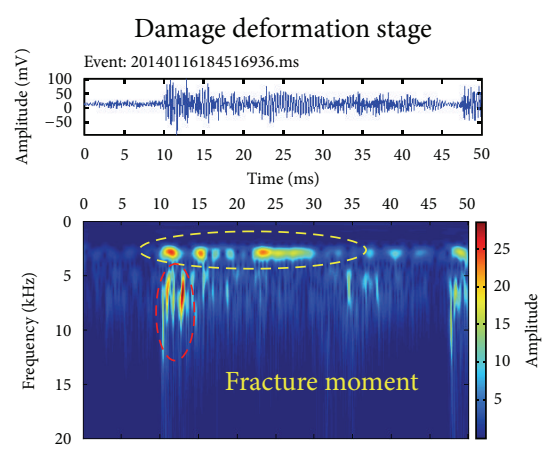

(i) $F=155 \mathrm{kN}, \sigma=\sigma_{c}$

FIGURE 7: Microseismic signal spectrum characteristics of concrete beam during fracture processes.

3.3. Analysis on Microseismic Signal Characteristics during the Fracture Process of the Concrete Beam. Figure 6 shows the characteristic curve of microseismic events during the three-point bending fracture processes of the concrete beam. After comprehensive analysis on the curves of the loading process, microseismic events per unit time, accumulative microseismic events per unit time, and strain, the following results can be obtained. (1) The curve of the accumulative microseismic events per unit time of the concrete model has a basically consistent change trend with the strain curve. (2) In the single-stage load process, the number of microseismic events per unit time of the concrete beam shows a jump and then appears an attenuation trend. (3) Based on the slope change rules of the strain curve and the curve of the total number of microseismic events per unit time, the fracture process of the concrete beam can be divided into three stages: elastic deformation stage (OD), plastic deformation stage (DG), and failure deformation stage (GH).

Figure 7 shows the spectrum characteristics of some typical microseismic signals on each stage of the failure processes of the concrete beam. The spectrum characteristics in the three stages of the fracture processes of the concrete beam are as follows.

(1) Elastic deformation stage (OD): $0 \sim 90 \mathrm{kN}$ load is imposed in this stage, with the corresponding stress $\sigma=0 \sim 0.58 \sigma_{c}\left(\sigma_{c}\right.$ is the maximum normal stress when the concrete beam fractures). This process mainly shows that the initial cracks in the middle and on both sides of the beam are compacted or tensioned. The generated microseismic signal spectrum is as shown in Figures 7(a), 7(b), and 7(c). In the elastic deformation stage of the concrete beam, the microseismic signal is mainly single-shock and spreads about $5 \mathrm{~ms}$ on the time axis of the spectrogram, with frequency 
ranging from 6 to $18 \mathrm{kHz}$ and concentrating within 6 to $12 \mathrm{kHz}$ range. The amplitude spectral value is small and the high frequency components of microseismic signals show a decay trend with increase of load and stress.

(2) Plastic deformation stage (DG): $90 \sim 140 \mathrm{kN}$ load is imposed in this stage, with the corresponding stress $\sigma=$ $0.65 \sim 0.90 \sigma_{c}$. This process shows that the initial cracks in the middle beam send microseismic signals after being compacted or tensioned; however, more microfractures in the middle gradually propagate and locally coalesce. The spectrum of the generated typical microseismic signal is as shown in Figures 7(d), 7(e), and 7(f). The microseismic signal in the plastic deformation stage of the concrete beam is multishock. It spreads about $15 \mathrm{~ms}$ on the time axis of the spectrogram. The signal has two dominant frequency bands: low frequency band around $3 \mathrm{kHz}$ and middle and high frequency brand ranging from 6 to $10 \mathrm{kHz}$. As the load and stress increase, the middle and high frequencies of microseismic signals show a decay trend whilst the low frequency shows an increase trend. Compared with the elastic deformation stage, the low frequency $(3 \mathrm{kHz})$ appears in this stage, which can be regarded as the precursor of concrete failure process.

(3) Failure deformation stage $(\mathrm{GH}): 145 \sim 155 \mathrm{kN}$ load is imposed in this stage, with the corresponding stress $\sigma=$ $0.94 \sim 1.0 \sigma_{c}$. This process shows that the initial cracks in the middle and on both sides of the beam send microseismic signals (relatively fewer and existing locally) after being compacted or tensioned. However, more microfractures in the middle beam gradually propagate and coalesce. The spectrum of the generated typical microseismic signal is as shown in Figures 7(g), 7(h), and 7(i). The microseismic signal in the failure deformation stage of the concrete beam is also multishock. It spreads about 15 to $20 \mathrm{~ms}$ on the time axis of the spectrogram. The signal has two dominant frequency bands: low frequency band around $3 \mathrm{kHz}$; middle and high frequency band ranging from 6 to $10 \mathrm{kHz}$ (high frequency ranging from 6 to $18 \mathrm{kHz}$ at the moment of failure). As the load and stress increase, the middle and high frequencies $(6 \sim 10 \mathrm{kHz})$ of microseismic signals show a decay trend whilst the low frequency $(3 \mathrm{kHz})$ shows an increase trend. When $\sigma=\sigma_{c}$, the low frequency is higher than the high frequency (as shown in Figure 7(h), the spectrogram is dominated by the low frequency). At the moment of the fracture of the concrete beam, the high frequency $(6 \sim 18 \mathrm{kHz})$ components and low frequency components $(3 \mathrm{kHz})$ obviously increase on the microseismic signal spectrogram (Figure 7(i)). When the spectrum of microseismic signals is dominated by low frequency $(3 \mathrm{kHz})$ and high frequency $(6 \sim 18 \mathrm{kHz})$ components, it can be regarded as the sign of concrete failure.

It can be seen that the spectrum characteristics of microseismic signals reproduce the three stages of concrete beam fracture and microseismic generation mechanism. To be specific, (1) the microscopic initial cracks of concrete are compacted or tensioned (cementing materials are compacted or tensioned); (2) concrete microfractures gradually propagate and locally coalesce under loading (cementing materials are compacted or tensioned; aggregate and cementing materials fall off); (3) concrete microfractures propagate, coalesce, and form macroscopic cracks under loading, thus causing concrete beam fracture.

3.4. Microseismic Evolution Rules during the Fracture Processes of the Concrete Beam. Figure 8 shows the spatial distribution evolution rules of microseismic events of the concrete beam under accumulated load. It intuitively reproduces the entire processes from microfractures initiation, development, propagation, and coalescence, until macroscopic fracture formation in the three-point bending test of the concrete beam. As shown in Figure 8, the evolution characteristics of microseismic events during the fracture process of the concrete beam can be summarized: (1) in the stage of crack initiation, when the force is exerted, the initial cracks in the middle and on both sides of the beam are compacted or tensioned, and microseismic events are randomly and discretely distributed on the concrete beam, as shown in Figures 8(a), 8(b), and 8(c); (2) in the stage of crack formation and propagation, as the load increases, microseismic events occur in the middle and on the right of the concrete beam but mainly concentrate in the middle and bottom of the beam, as shown in Figures 8(d) and 8(e); (3) in the crack coalescence stage, a large number of microseismic events mainly occur in the middle and bottom of the concrete beam, as shown in Figures 8(f), 8(g), and 8(h).

\section{Numerical Simulation of Concrete Beam Subjected to Three-Point Bending Fracture}

4.1. RFPA ${ }^{3 D}$ Code. The RFPA code was developed by Tang et al. [31-33] considering the deformation of an elastic material containing an initial random distribution of microfeatures in order to simulate more clearly the progressive failure, including the failure process, failure induced seismic events, and failure induced stress redistribution. To include the statistical variability of the bulk failure strength in RFPA code, the mechanical parameters of the model elements are assumed to follow a Weibull distribution [34]:

$$
W(x)=\frac{m}{x_{0}}\left(\frac{x}{x_{0}}\right)^{m-1} \exp \left[-\left(\frac{x}{x_{0}}\right)^{m}\right],
$$

where $m$ defines the shape of the Weibull distribution function, which can be referred to as the homogeneity index, $x$ is the mechanical parameter of an element, and $x_{0}$ is the even value of the parameter of all elements. According to the Weibull distribution, the larger the $m$ value, the more the elements with mechanical properties approaching the mean value, which depicts a more homogeneous rock specimen [35].

Compared with other numerical methods, the RFPA code features two merits [32]. One is that, by introducing heterogeneity of rock properties into the model, the code can simulate nonlinear deformation of a quasi-brittle behavior with an ideal brittle constitutive law at the local scale. The other is that, by introducing a reduction of material parameters after element failure, the RFPA code can simulate discontinuum mechanics problems in the frame of continuum mechanics. Details of the RFPA code can be seen in Tang and Kaiser [32]. 


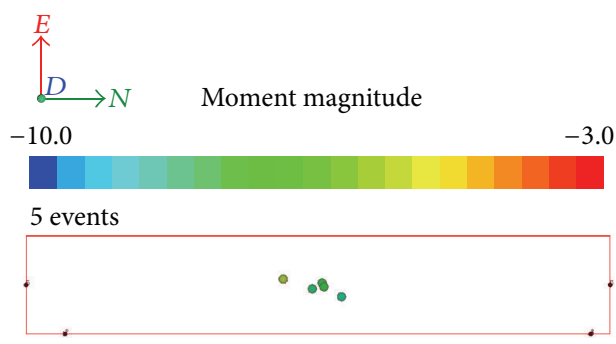

(a) $F=0 \sim 20 \mathrm{kN}$

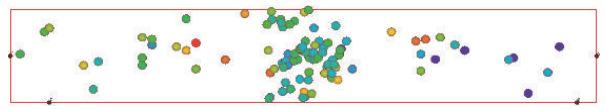

(c) $F=0 \sim 80 \mathrm{kN}$

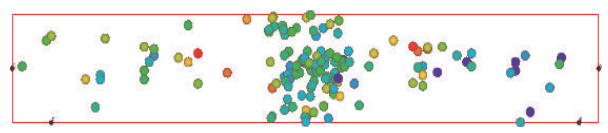

(e) $F=0 \sim 120 \mathrm{kN}$

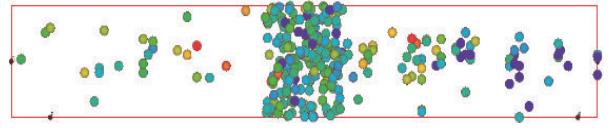

(g) $F=0 \sim 150 \mathrm{kN}$

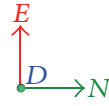

$-10.0$

Moment magnitude

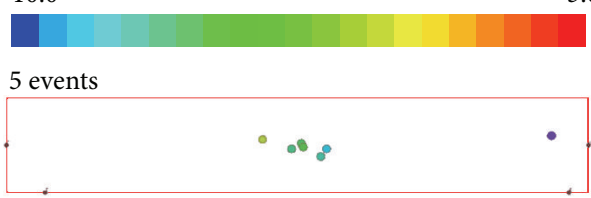

(b) $F=0 \sim 40 \mathrm{kN}$

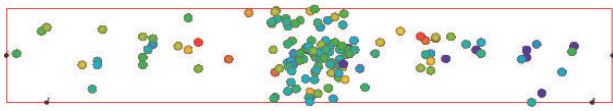

(d) $F=0 \sim 100 \mathrm{kN}$

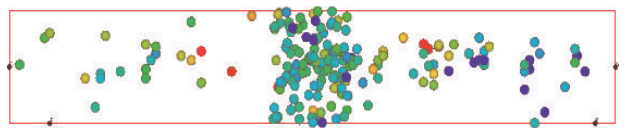

(f) $F=0 \sim 140 \mathrm{kN}$

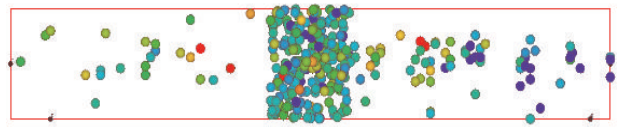

(h) $F=0 \sim 155 \mathrm{kN}$

Figure 8: Spatial distribution evolution of MS events of concrete beam during loading stages (see from NE viewing).

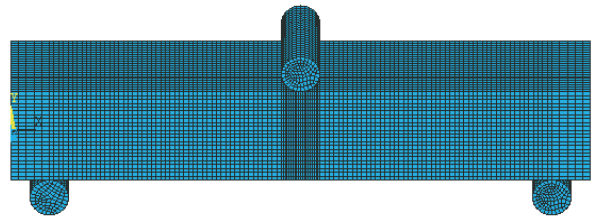

(a)

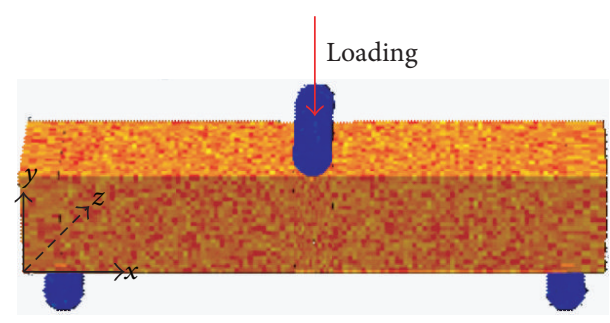

(b)

FIGURE 9: Calculation model (a) ANSYS model and (b) RFPA ${ }^{3 D}$ model.

The robustness of RFPA and its 3D extension in simulating rock fracture has been evaluated by many scholars $[10,11,31-$ $33,35]$.

4.2. Model Setup. Firstly, the ANSYS software is used to build a finite element model. The concrete beam has the cross section in dimensions of $500 \mathrm{~mm} \times 500 \mathrm{~mm}$ and is $3000 \mathrm{~mm}$ long. Both the support and loading steel roller are cylinder with a $20 \mathrm{~mm}$ diameter. The distance between two supports is $2500 \mathrm{~mm}$. Load transfer between the support, loading
TABLE 1: Macroscopic mechanical parameters of materials.

\begin{tabular}{lccc}
\hline Materials & $\begin{array}{c}\text { Elasticity } \\
\text { modulus/MPa }\end{array}$ & $\begin{array}{c}\text { Poisson's } \\
\text { ratio }\end{array}$ & $\begin{array}{c}\text { Compressive } \\
\text { strength/MPa }\end{array}$ \\
\hline Concrete & 28000 & 0.2 & 25 \\
Steel Roller & 210000 & 0.3 & 600 \\
\hline
\end{tabular}

steel tube, and concrete beam is realized by a common node. The model is divided into 75049 hexahedral elements and mesh encryption is performed on the main force part of the concrete beam. Figure 9 (a) shows mesh generation. Figure 9(b) shows the model after being imported to RFPA ${ }^{3 \mathrm{D}}$ considering concrete heterogeneity. The model constraint and load are imposed in the ANSYS. To be specific, the left support rebar is imposed with constraint in $\mathrm{X}$ and $\mathrm{Y}$ directions while the right support rebar is imposed with constraint in Y direction. Table 1 lists the material parameters of the finite element model. The concrete three-point bending test adopts the displacement-controlled stepwise loading mode, and the displacement loaded in each step is $0.02 \mathrm{~mm}$.

After being imported to RFPA ${ }^{3 \mathrm{D}}$, the mechanical parameters of the modeled material are converted from macroscopic parameters to microscopic parameters considering the material heterogeneity using the following equation:

$$
\begin{aligned}
& \frac{f_{1}}{f_{2}}=0.2602 \ln m+0.0233, \\
& \frac{E_{1}}{E_{2}}=0.1412 \ln m+0.6476 .
\end{aligned}
$$


TABLE 2: Mesoscopic mechanics parameters of materials in RFPA ${ }^{3 \mathrm{D}}$ model.

\begin{tabular}{lcccc}
\hline Materials & Elasticity modulus/MPa & Poisson's ratio & Compressive strength/MPa & Heterogeneity \\
\hline Concrete & 33200 & 0.2 & 65 & 4 \\
Steel Roller & 210000 & 0.3 & 600 & 100 \\
\hline
\end{tabular}

In the preceding equation, $m$ is the homogeneity; $f_{1}$ is the macroscopic strength; $f_{2}$ is the microscopic strength; $E_{1}$ is the macroscopic elastic modulus; $E_{2}$ is the microscopic elastic modulus. The homogeneity $m$ of the concrete is set as 4 while that of the homogeneous support and loading steel roller is set to 100 . The material mechanical parameters in Table 1 are converted to microscopic parameters in $\mathrm{RFPA}^{3 \mathrm{D}}$ by using (9), as listed in Table 2.

4.3. Numerical Simulation Results. Figure 10 shows the change rules of the loading force, loaded displacement, and $\mathrm{AE}$ of concrete beam during the three-point bending test. In $\mathrm{RFPD}^{3 \mathrm{D}}$ numerical simulation, the element failure is accompanied by $\mathrm{AE}$, and the number of AEs is that of failed elements. Figure 10 shows the relation between the loaded displacement and AE, including the bar chart of AEs generated by the specimen in each loading and the total number of AEs during the entire loading processes.

Figure 11 shows the maximum principal stress and AE of the concrete beam during the three-point bending fracture process. The maximum principal stress figure shows a fixed section of the concrete beam while the blue spheres in the $\mathrm{AE}$ figure represent the tensile failure elements. It can be seen that, when it is loaded to step 7 (point A in Figure 10), the load reaches $48 \mathrm{kN}$; the specimen starts to initiate microfractures. As the loaded displacement constantly increases, microfractures gradually become more and the growth rate becomes faster and faster. When it is loaded to step 23, the load on the specimen reaches the peak value $148 \mathrm{kN}$ (point B in Figure 10). Then, a large number of microfractures occur on mid-span of the bottom concrete beam (as shown on step 23 in Figure 11(b)) and a group of microfractures initiate on the bottom of concrete beam perpendicular to its axial direction (as shown on step 23 in Figure 11(a)). This is mainly because the maximum tensile stress occurs in the middle of the bottom beam during the three-point bending test, causing stress concentration. Before this, the concrete beam always shows linear elastic deformation ( $\mathrm{AB}$ in Figure 10). When loading continues, the stress at the initial crack tip on the beam bottom is highly concentrated. Therefore, the main cracks start to initiate at the tip of microfractures and are on the same planes with the initial cracks. The bearing capacity of the beam reduces rapidly and shows its nonlinear characteristics (BC in Figure 10). A large number of tensile failure points continue to gather in the middle of the bottom concrete beam and gradually migrate and evolve to the beam top. When loading reaches step 30 (point C in Figure 10), the propagation length of the crack is about half of the beam height and the crack continues to propagate to the beam top in the vertical direction. According to Figure 10, when the test loading reaches step 40 (point D in Figure 10), the number of AEs hardly increases and those AEs form a vertical fracture

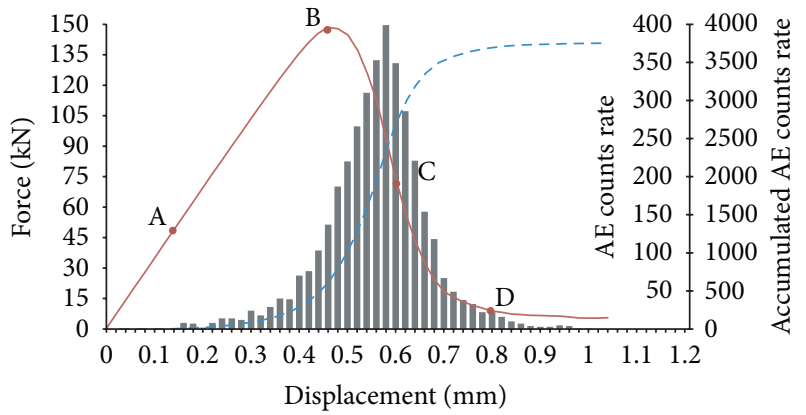
(A) $48 \mathrm{kN} 32 \% P_{\text {peak }}$
AE counts rate
(B) $148 \mathrm{kN} 100 \% P_{\text {peak }}$
- Force-displacement curve
(C) $73 \mathrm{kN}$ post $50 \% P_{\text {peak }}$
(D) $8.8 \mathrm{kN}$ post $6 \% P_{\text {peak }}$
- - Accumulated AE counts rate

FIGURE 10: Variation of the test load, displacement, and AE of the concrete beam subjected to three-point bending.

band in the middle of the concrete beam (as shown on step 40 in Figure 11(b)). The cracks run through the concrete beam. The beam has almost no bearing capacity, and the specimen completely fails.

It can be seen that numerical simulation used by RFPA ${ }^{3 \mathrm{D}}$ reproduces the entire processes of the concrete beam from its microfractures initiation, development, propagation, and coalescence, until macroscopic fracture band formation in the three-point bending tests. The numerical results reveal the failure modes and fracture mechanism of the concrete beam in different deformation stages.

\section{Comparative Analysis of Field Test and Numerical Simulation Results}

Figure 12 shows the AE from numerical simulation and field test. It can be seen that, when the load is started to be imposed, microfractures are randomly distributed on the beam model in the initial loading stage because the initial cracks in the middle and on both sides of the concrete beam are compacted or tensioned. When the specimen finally fractures, the AE obtained from numerical simulation agrees well with the accumulated spatial distribution of microseismic events obtained from field microseismic monitoring. That is, most microfractures concentrate in the middle of the concrete beam as shown in Figure 12.

Figure 13 shows the final fracture maps of the concrete beam obtained from numerical simulation and field test, respectively. It can be seen that, during the three-point bending fracture processes of the concrete beam, the cracks do not always initiate along the vertical direction. That is mainly because of the heterogeneity of concrete, which causes 


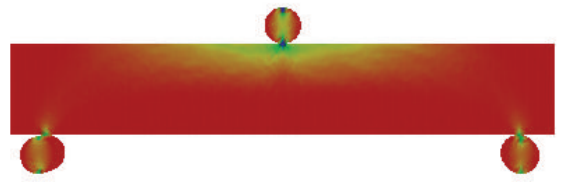

Step $7(F=32 \%$ peak force $)$

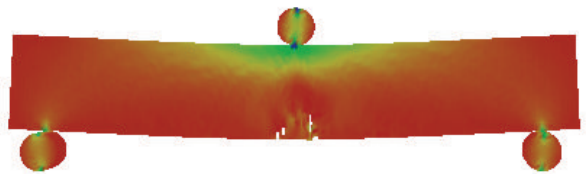

Step $23(F=100 \%$ peak force $)$

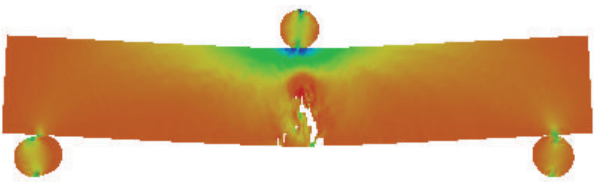

Step $30(F=$ post $50 \%$ peak force $)$

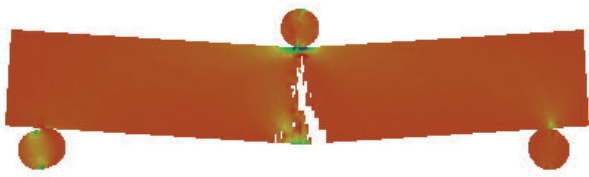

Step $40(F=$ post $7 \%$ peak force $)$

(a) The maximum principal stress
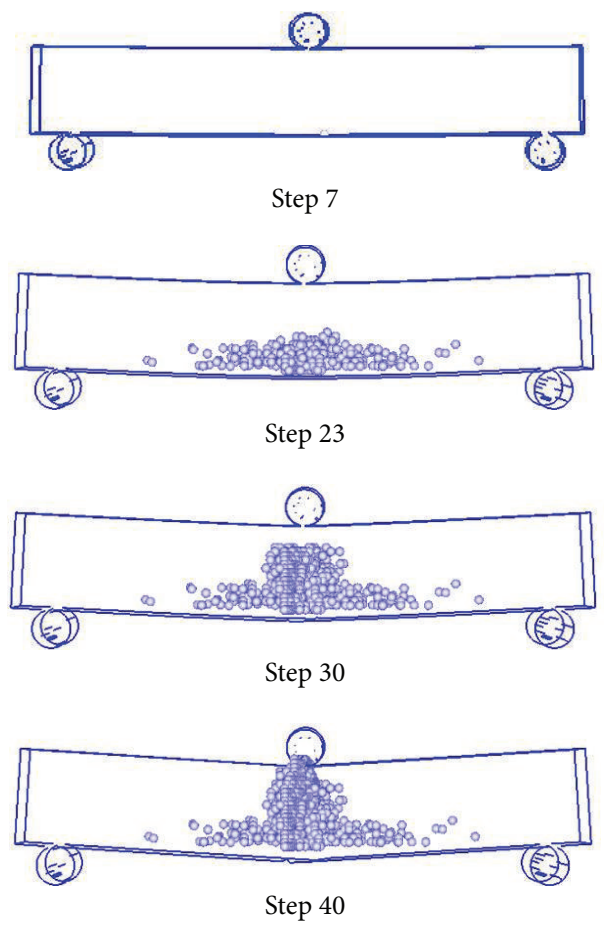

(b) AE distribution

FIgURE 11: The failure processes of the concrete beam.
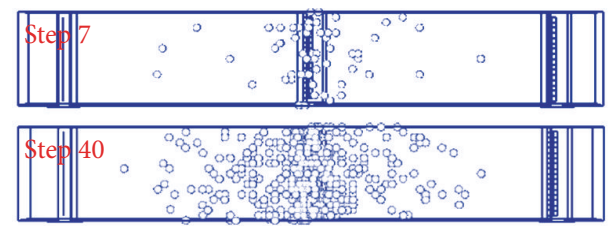

(a)

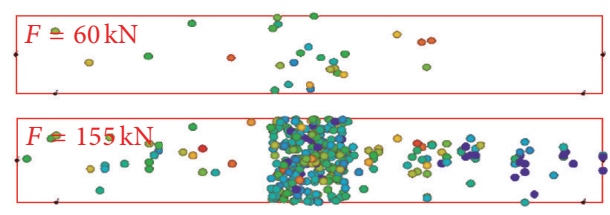

(b)

FIGURE 12: Comparison of spatial distribution of AE/MS between numerical simulation and microseismic monitoring results. (a) $\mathrm{AE}$ obtained from numerical simulation; (b) MS obtained from field test.

a zigzag propagation path of the cracks. The heterogeneity of concrete is taken into account during $\mathrm{RPFA}^{3 \mathrm{D}}$ numerical simulation for the fracture process of the concrete beam. The tough aggregates (elements with high strength in the numerical model) can prevent the cracks from propagating forwards. Instead, most cracks propagate along the cementing band around the aggregate, and therefore the crack propagation paths are zigzag. Numerical simulation results (Figure 13(a)) agree well with the field physical test results (Figure 13(b)).
Consequently, the heterogeneity of concrete is the major cause of zigzag propagation paths of beam cracks subjected to three-point bending tests [36].

Furthermore, the bearing capacity of the concrete beam obtained from the field three-point bending test is $155 \mathrm{kN}$ (as shown in Figures 6 and 8) while the bearing capacity obtained from numerical simulation is $148 \mathrm{kN}$ (as shown in Figure 10), with a $4.5 \%$ relative error. It can be seen that the three-point bending fracture test results of the concrete beam obtained from numerical simulation are basically consistent with the field physical test results.

\section{Conclusions}

Microseismic monitoring is conducted on the three-point bending fracture processes of the field RCC beam. The spectrum characteristics of microseismic signals of concrete failure and its formation mechanism are revealed. The identification method of the fracture stages and crack propagation precursors of concrete is established. Numerical simulation reproduces the entire processes of the concrete beam rupture from microfractures initiation, development, propagation, and coalescence, until macroscopic fracture formation. The different failure modes and mechanism of the concrete beam rupture are thus revealed. The main conclusions are drawn as follows.

(1) When the specimen is under the plastic deformation stage, the microseismic signal is mainly multishock. The spectrum spreads about $15 \mathrm{~ms}$ on the time axis. 


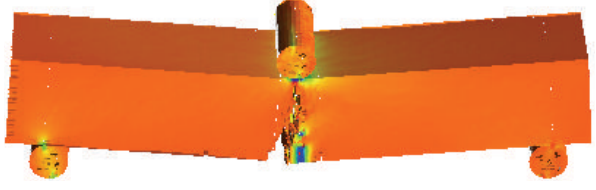

(a) Concrete beam rupture from numerical simulation
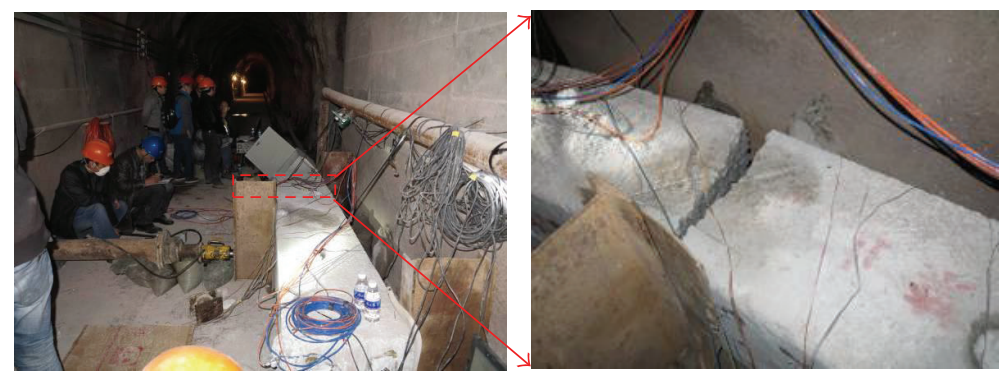

(b) Comparison map of concrete beam before and after rupture

Figure 13: Final rupture of the concrete beam.

The signal has two dominant frequency bands: low frequency band around $3 \mathrm{kHz}$ and the middle and high frequency band ranging from 6 to $10 \mathrm{kHz}$. When the microseismic signal spectrum shows $3 \mathrm{kHz}$ "low frequency shadow," it can be regarded as the precursor signal of the concrete failure. The microseismic signal at the moment of specimen failure is also mainly multishock. The spectrum spreads more than $20 \mathrm{~ms}$ on the time axis. The signal also has two dominant frequency bands: low frequency band around $3 \mathrm{kHz}$ and high frequency band ranging from 6 to $18 \mathrm{kHz}$. The amplitude spectral value is relatively high. That is, when the spectrum shows that the microseismic signals are dominated by $3 \mathrm{kHz}$ "low frequency shadow" and 6 to $18 \mathrm{kHz}$ "high frequency shadow," concrete already fractures macroscopically.

(2) The RFPA ${ }^{3 D}$ code is adopted to simulate the threepoint bending test of concrete beam. The heterogeneity of concrete is taken into account. Numerical simulation reproduces the entire deformation and failure processes of the specimen subjected to threepoint bending test. The relation between the load, displacement, and $\mathrm{AE}$ during the deformation and failure process of the specimen, as well as the cracks propagation processes and stress field distribution rules, is obtained.

(3) The fracture mode of the RCC beam revealed from numerical simulation agrees well with the field physical test results. During the loading processes, microfractures firstly initiate on the mid-span of the bottom concrete beam. Under loading, these microfractures constantly initiate, develop, gradually propagate along the vertical direction of the beam, coalesce, and form main failure fractures, finally causing macroscopic fractures of the concrete beam. The heterogeneity of concrete is the major cause of zigzag propagation paths of beam cracks subjected to three-point bending tests.

\section{Conflict of Interests}

The authors declare that there is no conflict of interests regarding the publication of this paper.

\section{Acknowledgments}

The authors are grateful for the financial support from the National Program on Key basic Research Project (no. 2015CB057903), National Natural Science Foundation of China (nos. 51209127 and 51374149), the Program for New Century Excellent Talents in University (NCET-13-0382), Sichuan Provincial Youth Science and Technology Fund (2014JQ0004), and the opening fund of State Key Laboratory of Hydrology-Water Resources and Hydraulic Engineering, Nanjing Hydraulic Research Institute (no. 2012491711).

\section{References}

[1] P. Lin, S. Kang, Q. Li, R. Wang, and Z. Wang, "Evaluation of rock mass quality and stability analysis of Xiluodu arch dam under construction phase," Chinese Journal of Rock Mechanics and Engineering, vol. 31, no. 10, pp. 2042-2052, 2012 (Chinese).

[2] S. Song and D. Cai, "Earthquake damage phenomena and deformation monitoring analysis for concrete faced rockfill dam at Zipingpu project during wenchuan earthquake," Chinese Journal of Rock Mechanics and Engineering, vol. 28, no. 4, pp. 840-849, 2009 (Chinese).

[3] F. W. Xu and B. Tian, "Analysis of contributing factors to cracks of high arch dam," Hubei Water Power, vol. 59, no. 2, pp. 14-17, 2005 (Chinese).

[4] Y. Liu, J. Wang, Q. Yang, R. Yang, and W. Zhou, "Research on influences of cracking of Xiaowan arch dam on its stress and stability," Chinese Journal of Rock Mechanics and Engineering, vol. 29, no. 6, pp. 1132-1139, 2010 (Chinese).

[5] Z.-Y. Shu, J. Xiong, and L.-G. Li, "Crack genetic analysis and countermeasure research of Side dam," Journal of Sichuan University (Engineering Science Edition), vol. 39, no. 3, pp. 1218, 2007 (Chinese).

[6] F. H. Ma, "Crack cause analysis of Shangbiao concrete arch dam," Water Resources and Power, vol. 19, no. 4, pp. 16-19, 2001 (Chinese).

[7] A. J. Mendecki, Seismic Monitoring in Mines, Chapman \& Hall, London, UK, 1997.

[8] M. Cai, P. K. Kaiser, and C. D. Martin, "Quantification of rock mass damage in underground excavations from microseismic event monitoring," International Journal of Rock Mechanics and Mining Sciences, vol. 38, no. 8, pp. 1135-1145, 2001.

[9] R. A. Lynch, R. Wuite, B. S. Smith, and A. Cichowicz, "Microseismic monitoring of open pit slopes," in Proceedings of the 6th 
Symposium on Rockbursts and Seismicity in Mines, Y. Potvin and M. Hudyma, Eds., pp. 581-592, ACG, Perth, Australia, 2005.

[10] N. W. Xu, F. Dai, Z. Z. Liang, Z. Zhou, C. Sha, and C. A. Tang, "The dynamic evaluation of rock slope stability considering the effects of microseismic damage," Rock Mechanics and Rock Engineering, vol. 47, no. 2, pp. 621-642, 2014.

[11] N. W. Xu, C. A. Tang, L. C. Li et al., "Microseismic monitoring and stability analysis of the left bank slope in Jinping first stage hydropower station in southwestern China," International Journal of Rock Mechanics \& Mining Sciences, vol. 48, no. 6, pp. 950-963, 2011.

[12] M. Ge, "Efficient mine microseismic monitoring," International Journal of Coal Geology, vol. 64, no. 1-2, pp. 44-56, 2005.

[13] H. Wang and M. Ge, "Acoustic emission/microseismic source location analysis for a limestone mine exhibiting high horizontal stresses," International Journal of Rock Mechanics and Mining Sciences, vol. 45, no. 5, pp. 720-728, 2008.

[14] A. Leśniak and Z. Isakow, "Space-time clustering of seismic events and hazard assessment in the Zabrze-Bielszowice coal mine, Poland," International Journal of Rock Mechanics and Mining Sciences, vol. 46, no. 5, pp. 918-928, 2009.

[15] A. Hirata, Y. Kameoka, and T. Hirano, "Safety management based on detection of possible rock bursts by AE monitoring during tunnel excavation," Rock Mechanics and Rock Engineering, vol. 40, no. 6, pp. 563-576, 2007.

[16] C. A. Tang, J. M. Wang, and J. J. Zhang, "Preliminary engineering application of microseismic monitoring technique to rockburst prediction in tunneling of Jinping II project," Joumal of Rock Mechanics and Geotechnical Engineering, vol. 2, no. 3, pp. 193-208, 2011.

[17] S. L. Li, "Discussion on microseismic monitoring technology and its application to underground project," Chinese Journal of Underground Space and Engineering, vol. 5, no. 1, pp. 122-128, 2009 (Chinese).

[18] K. Tezuka and H. Niitsuma, "Stress estimated using microseismic clusters and its relationship to the fracture system of the Hijiori hot dry rock reservoir," Engineering Geology, vol. 56, no. 1-2, pp. 47-62, 2000.

[19] H.-H. Zhu, J.-H. Yin, L. Zhang, W. Jin, and J.-H. Dong, "Monitoring internal displacements of a model dam using FBG sensing bars," Advances in Structural Engineering, vol. 13, no. 2, pp. 249-261, 2010.

[20] H.-H. Zhu, J.-H. Yin, J.-H. Dong, and L. Zhang, "Physical modelling of sliding failure of concrete gravity dam under overloading condition," Geomechanics and Engineering, vol. 2, no. 2, pp. 89-106, 2010.

[21] J. Xu, R.-H. Yang, J.-G. Zhang, and Z.-Y. Xu, "A preliminary study on precursors of strong fracture in brittle material specimens," Chinese Journal of Geophysics, vol. 54, no. 9, pp. 2283-2292, 2011 (Chinese).

[22] Y. Gong, M. He, Z. Wang, and Y. Yin, "Research on timefrequency analysis algorithm and instantaneous frequency precursors for acoustic emission data from rock failure experiment," Chinese Journal of Rock Mechanics and Engineering, vol. 32, no. 4, pp. 787-799, 2013.

[23] C. Lu, L. Dou, X. Wu, Z. Mou, and G. Chen, "Experimental and empirical research on frequency-spectrum evolvement rule of rockburst precursory microseismic signals of coal-rock," Chinese Journal of Rock Mechanics and Engineering, vol. 27, no. 3, pp. 519-525, 2008 (Chinese).
[24] R. G. Stockwell, L. Mansinha, and R. P. Lowe, "Localization of the complex spectrum: the S-transform," IEEE Transactions on Signal Processing, vol. 44, no. 4, pp. 998-1001, 1996.

[25] Y.-Y. Tan, C. He, Y.-D. Wang, and Z. Zhao, "Ground roll attenuation using a time-frequency dependent polarization filter based on the S transform," Applied Geophysics, vol. 10, no. 3, pp. 279-294, 2013.

[26] Y. Z. Wang, J. T. Lan, and Y. S. Long, "The method for attenuating random noise based on $\mathrm{S}$ transform," Progress in Geophys, vol. 25, no. 2, pp. 562-567, 2010.

[27] J. P. Castagna, S. Sun, and R. W. Siegfried, "Instantaneous spectral analysis: detection of low-frequency shadows associated with hydrocarbons," The Leading Edge, vol. 22, no. 2, pp. 120 127, 2003.

[28] X. H. Chen, Z. H. He, D. J. Huang, and X. T. Wen, "Low frequency shadow detection of gas reservoirs in time-frequency domain," Chinese Journal of Geophysics, vol. 52, no. 1, pp. 215221, 2009 (Chinese).

[29] C. R. Pinnegar and L. Mansinha, "The S-transform with windows of arbitrary and varying shape," Geophysics, vol. 68, no. 1, pp. 381-385, 2003.

[30] G. Andria, M. Savino, and A. Trotta, "Application of WignerVille distribution to measurements on transient signals," IEEE Transactions on Instrumentation and Measurement, vol. 43, no. 2, pp. 187-193, 1994.

[31] C. A. Tang, "Numerical simulation of progressive rock failure and associated seismicity," International Journal of Rock Mechanics and Mining Sciences, vol. 34, no. 2, pp. 249-261, 1997.

[32] C. A. Tang and P. K. Kaiser, "Numerical simulation of cumulative damage and seismic energy release during brittle rock failure-part I: fundamentals," International Journal of Rock Mechanics and Mining Sciences, vol. 35, no. 2, pp. 113-121, 1998.

[33] C. A. Tang, H. Liu, P. K. K. Lee, Y. Tsui, and L. G. Tham, "Numerical studies of the influence of microstructure on rock failure in uniaxial compression. Part I. Effect of heterogeneity," International Journal of Rock Mechanics and Mining Sciences, vol. 37, no. 4, pp. 555-569, 2000.

[34] W. Weibull, "A statistical distribution functions of wide application," Journal of Applied Mechanics, vol. 18, pp. 293-297, 1951.

[35] Z. Z. Liang, H. Xing, S. Y. Wang, D. J. Williams, and C. A. Tang, "A three-dimensional numerical investigation of the fracture of rock specimens containing a pre-existing surface flaw," Computers and Geotechnics, vol. 45, pp. 19-33, 2012.

[36] W. C. Zhu, S. H. Wang, and C. A. Tang, "Computer simulation on the three-point bending test of concrete specimen," Journal of Northeastern University (Natural Science), vol. 20, no. 5, pp. 533-535, 1999 (Chinese). 

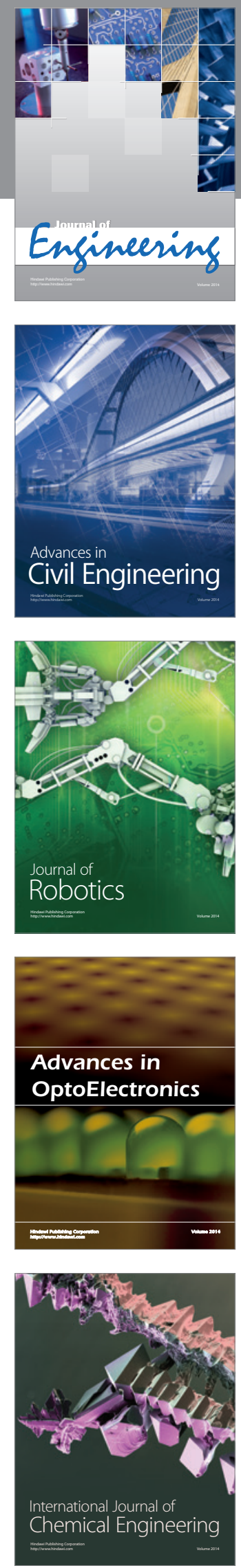

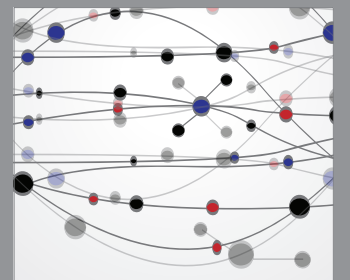

The Scientific World Journal
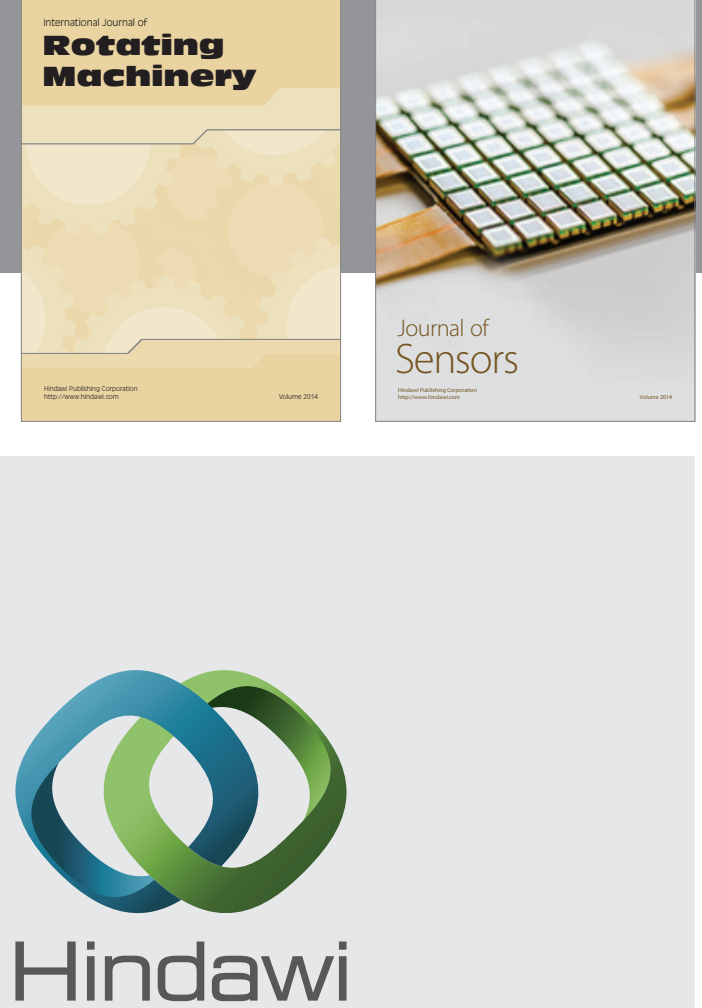

Submit your manuscripts at http://www.hindawi.com
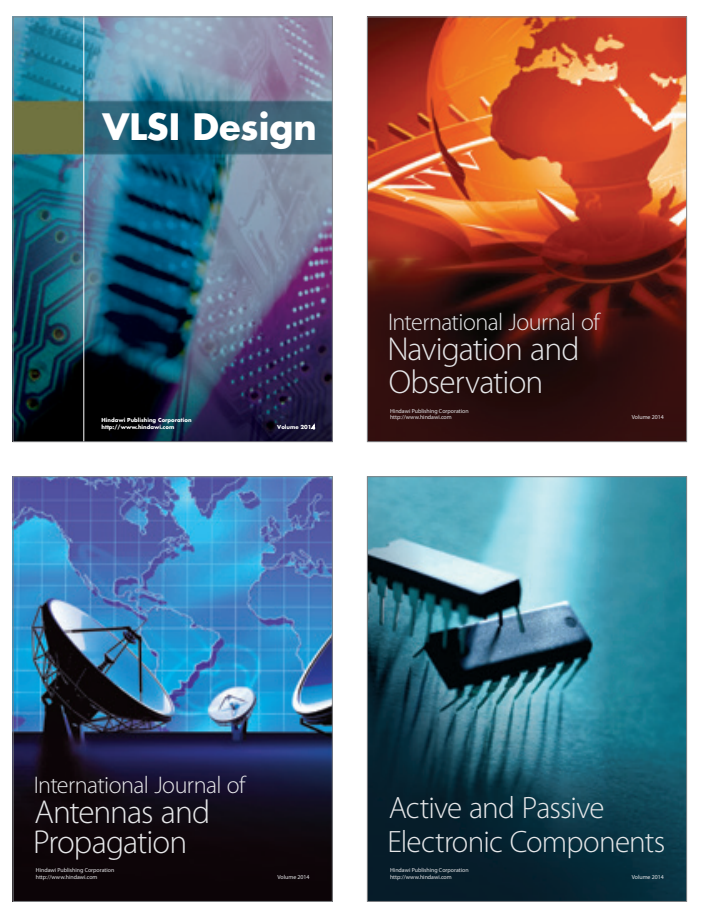
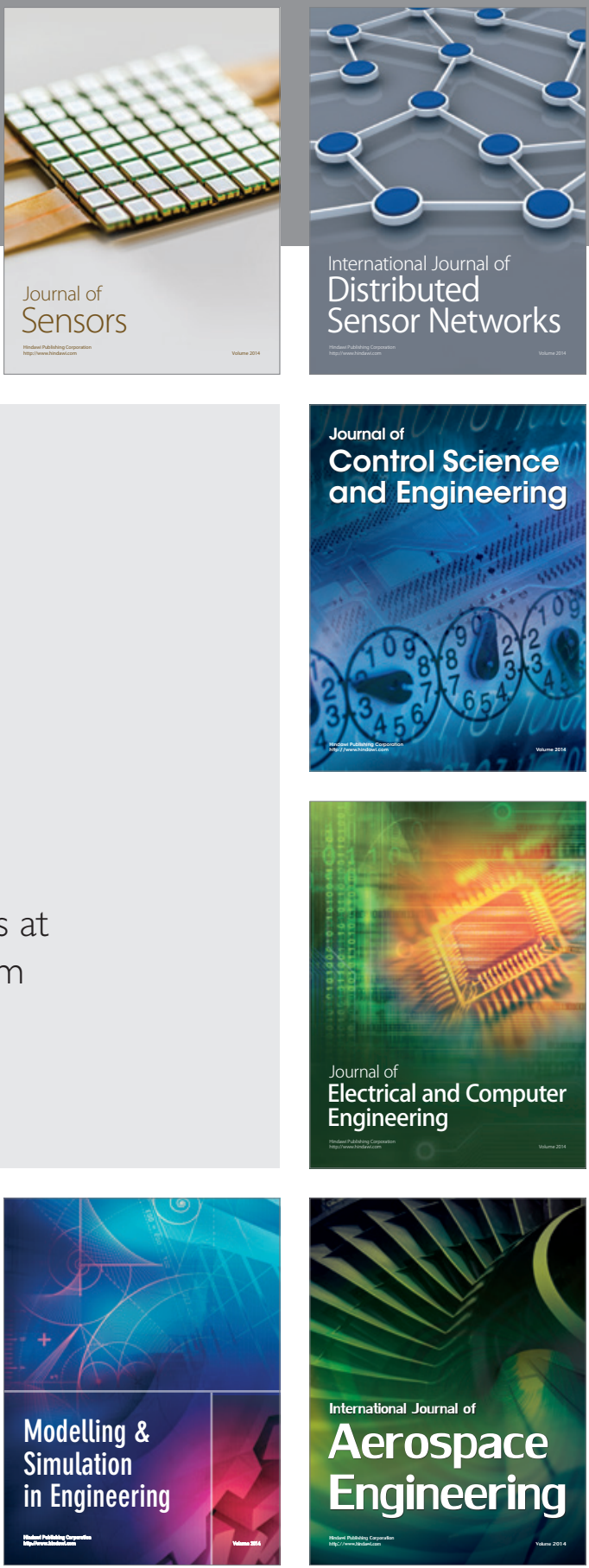

Journal of

Control Science

and Engineering
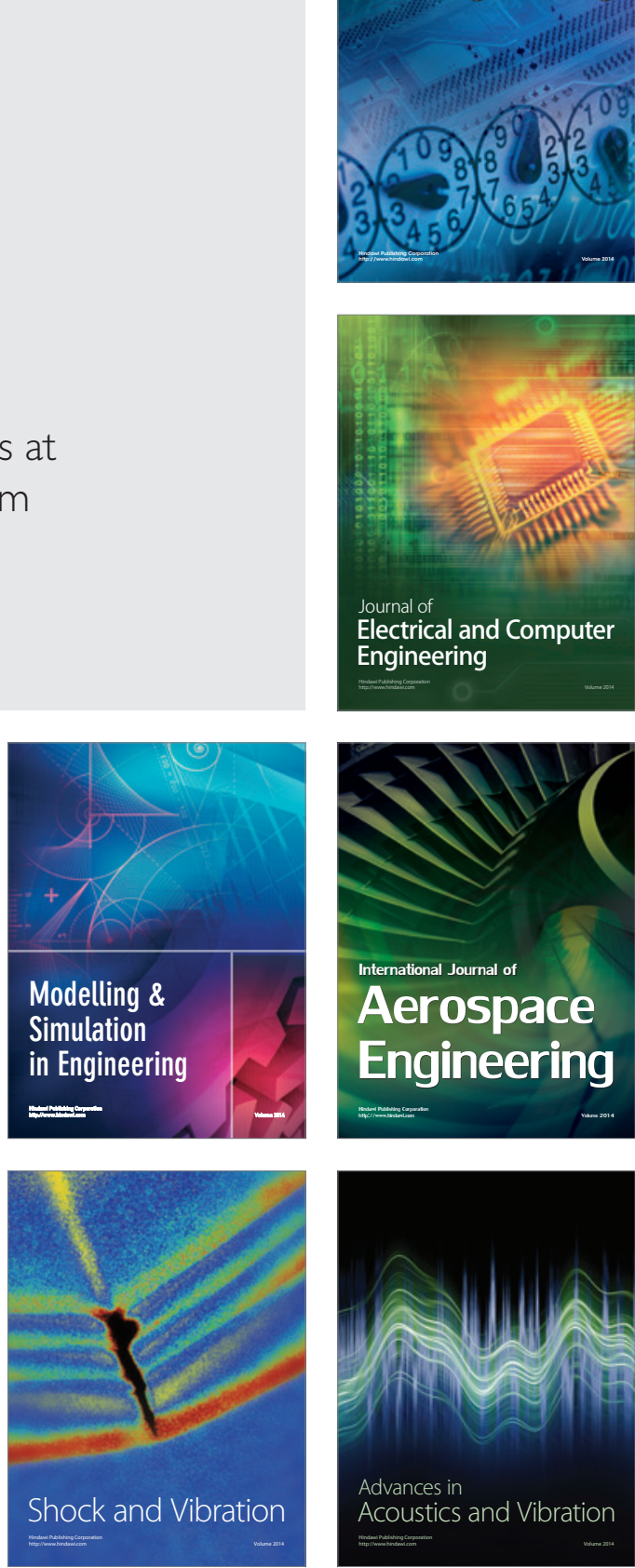